\title{
SIALOLITHIASIS- A REPORT OF TWO CASES AND REVIEW
}

\author{
Kapil Rathore1, Chitra Chakravarthy², Sanjay Sunder ${ }^{3}$, Ravi Patil4, Gururaj Arakeri ${ }^{5}$
}

${ }_{1}^{1}$ Post Graduate Student, Department of Oral \& Maxillofacial Surgery, NET’S Navodaya Dental College \& Hospital, Raichur, Karnataka, India.

2Professor and HOD, Department of Oral \& Maxillofacial Surgery, NET'S Navodaya Dental College \& Hospital, Raichur, Karnataka, India.

3Professor, Department of Oral \& Maxillofacial Surgery, NET'S Navodaya Dental College \& Hospital, Raichur, Karnataka, India. ${ }^{4}$ Reader, Department of Oral \& Maxillofacial Surgery, NET'S Navodaya Dental College \& Hospital, Raichur, Karnataka, India. ${ }^{5}$ Reader, Department of Oral \& Maxillofacial Surgery, NET'S Navodaya Dental College \& Hospital, Raichur, Karnataka, India.

\section{ABSTRACT}

Salivary gland calculi account for the most common disease of the salivary glands, and may range from tiny particles to several centimetres in size. The majority of sialoliths occur in the submandibular gland or its duct and is a common cause of acute and chronic infections. While the majority of salivary stones are asymptomatic or cause minimal discomfort, larger stones may interfere with the flow of saliva and cause pain and swelling. This case report describes two patients presenting with submandibular gland sialolith and also provides a literature review regarding the salivary sialolithiasis.

\section{KEYWORDS}

Sialolith, Submandibular Gland, Sialolithotomy.

HOW TO CITE THIS ARTICLE: Rathore K, Chakravarthy C, Sunder S, et al. Sialolithiasis- a report of two cases and review. J. Evolution Med. Dent. Sci. 2016; 5(9):393-396, DOI: 10.14260/jemds/2016/90

\section{INTRODUCTION}

Sialoliths are calcified organic matter that forms within the secretory system of the major salivary glands. ${ }^{1}$ These are calcareous deposits in the ducts of major or minor salivary glands or within the glands themselves. Sialolithiasis is a pathological condition caused by the obstruction of a salivary gland or its excretory duct by a calculus. It accounts for more than $50 \%$ of diseases of the major salivary glands and is thus frequently the cause of acute and chronic infections. Most common diseases of submandibular gland are seen in middleaged adults with male predilection. Males are affected twice as much as females. ${ }^{2}$ It is often seen in submandibular gland (80$92 \%)$ followed by parotid gland (6-20\%), sublingual and minor salivary glands (1-2\%). ${ }^{3}$ Intraductal stones occur more commonly than intraglandular stones. ${ }^{4}$ The incidence being 12 in 1000 persons for the adult population. ${ }^{5}$

The concentration of mucus is higher in the submandibular gland, accounting for the viscous nature of its secretions relative to the other salivary glands. This increased viscosity and subsequent relatively slower flow contributes to the propensity for submandibular salivary gland calculi.

We are reporting two cases of submandibular gland sialolith and review of the literature regarding the salivary sialolithiasis.

\section{Case 1}

A 19-year-old male patient reported with complaint of pain and foul taste since 2 months. He had episodes of left submandibular swelling occurring with meals.

Financial or Other, Competing Interest: None.

Submission 17-12-2015, Peer Review 09-01-2016,

Acceptance 19-01-2016, Published 01-02-2016.

Corresponding Author:

Dr. Kapil Rathore,

\# 402, IV Floor Balaji Heights, Plot Number 123,

Sector New 50, Seawoods, Darave,

Navi Mumbai, India- 400706

E-mail: rkapilrathorepg123@yahoo.com

DOI: $10.14260 /$ jemds $/ 2016 / 90$
These symptoms disappeared within relatively short periods ( 2 hours). Intraoral examination revealed a swelling localized in the left side of the floor of the mouth in relation to premolars, firm to hard on palpation and not adherent to deeper structure (Fig. 1).

The diagnosis of giant salivary calculus of the submandibular gland duct was confirmed by intraoral examination, transoral occlusal radiograph and Orthopantomogram (OPG) that showed a radiopaque oval shaped mineralized structure about $18 \mathrm{~mm}$ long and $6 \mathrm{~mm}$ large located in floor of mouth in the anterior region (Fig. 2 and 3). Also ultrasonography was done to rule out the exact position of the calculi (Fig. 4). Non-steroidal anti-inflammatory drug and antibiotics (Amoxicillin 1g t.i.d. and Metronidazole $400 \mathrm{mg}$ t.i.d., Diclofenac t.i.d.) were prescribed for a period of six days. Once the symptoms were under control, the surgical removal of the calculus was planned.

Surgery was performed under general anaesthesia and all aseptic conditions were duly maintained. Intraoral incision was placed along the course of duct on mucosa, blunt dissection was carried out and duct identified. Once the sialolith was located, it was distally fixed with a suture in order to prevent any movement along the duct during the procedure. Longitudinal incision was placed on the duct and a small pressure exerted at the level of the distal ligature that provoked the discharge of the sialolith through the incision (Fig. 5). Closure was done in layers using 3.0 Vicryl. Postoperative occlusal radiograph was clear with no sialoliths left out (Fig. 6). A follow-up of the same patient after 6 months showed no recurrence. 


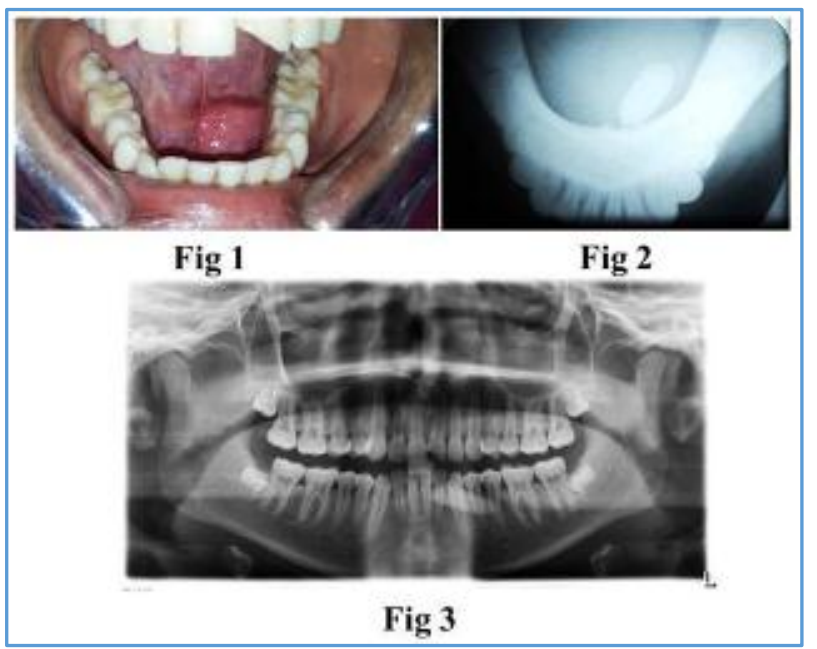

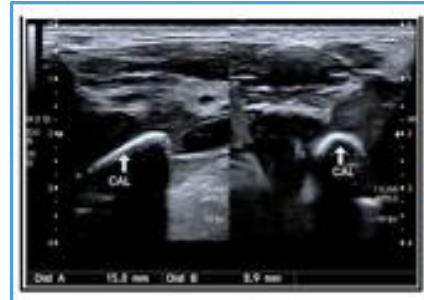

Fig 4

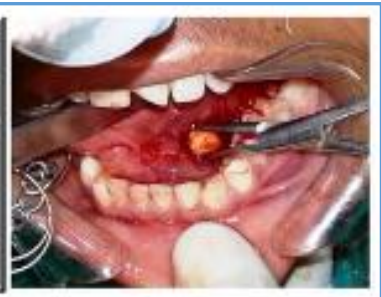

Fig 5

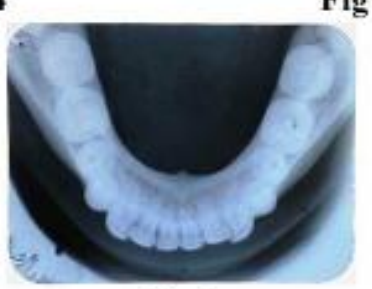

Fig 6

\section{Case 2}

A 22-year-old female patient reported with a complaint of pain in the floor of the mouth since six months, which aggravated during meals. On examination by bimanual palpation, firm to hard mass was felt in the region opposite to 33 and 34 and another mass was felt opposite to 35 and 36 (Fig. 7).
The patient was further subjected to radiological investigation and occlusal radiograph confirmed the clinical diagnosis of submandibular sialolithiasis, on both sides (Fig. 8). Ultrasonography report also proved the same. The sialolith present opposite to 33 and 34 was removed under local anesthesia with adrenaline; the incision was placed along the long axis of the duct as it was very close to the ductal orifice and superficial. The other two sialoliths were planned under general anesthesia by intraoral approach and were removed successfully (Fig. 9, 10). Postoperative occlusal radiograph was clear with no sialoliths left out (Fig. 11). A follow-up of the same patient after 6 months showed no recurrence.

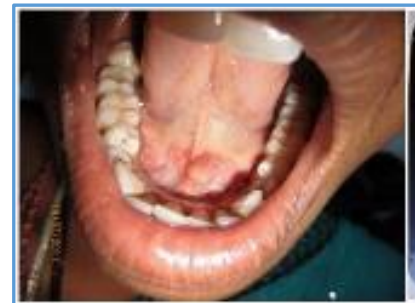

Fig 7

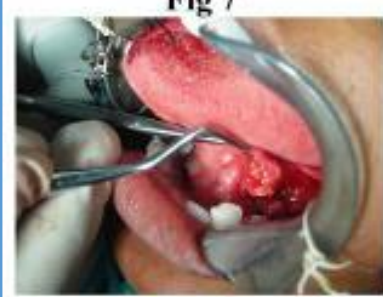

Fig 9

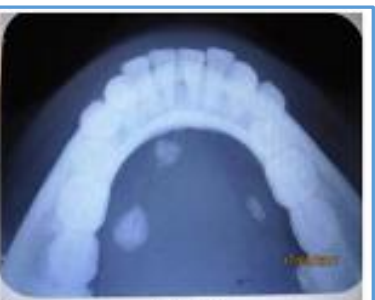

Fig 8

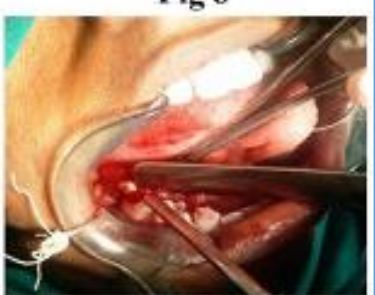

Fig 10

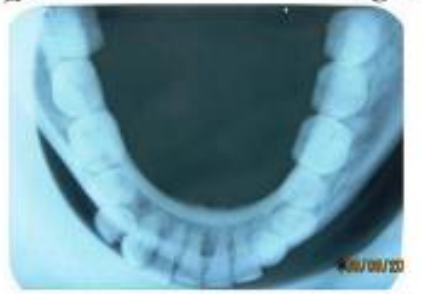

Fig 11

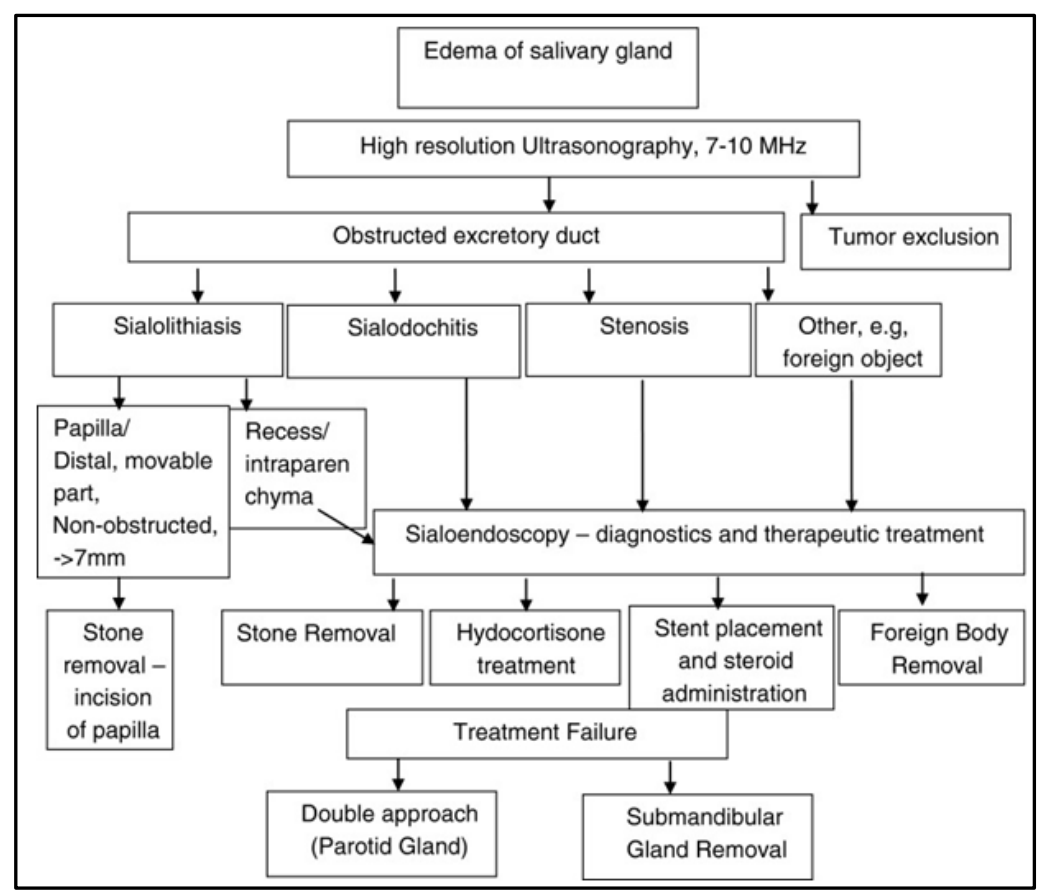




\section{DISCUSSION}

The deposition of calcium salts, primarily calcium phosphate, usually occurs in the skeleton. When it occurs in an unorganized fashion in soft tissue, it is referred to as heterotopic calcification. Heterotopic calcification which results from deposition of calcium in normal tissue despite normal serum calcium and phosphate levels is known as idiopathic calcification. Sialoliths belongs to the category of idiopathic calcification. ${ }^{1}$ Different aetiological hypotheses have been put forward for salivary gland calculi: mechanical, inflammatory, chemical, neurogenic, infectious, strange bodies, etc. It seems that the combination of a variety of these factors usually determines the precipitation of the amorphous tricalcic phosphate, which once crystallized and transformed into hydroxyapatite becomes the initial focus. ${ }^{6}$ From this moment on, it acts as a catalyst that attracts and supports the proliferation of new deposits of different substances.

According to literature, formation of sialolith can occur in two phases: A central core and a layered periphery. ${ }^{7}$ the central core is formed by the precipitation of salts, which are bound by certain organic substances. The second phase consists of the layered deposition of organic and inorganic material.8 Another theory has proposed that an unknown metabolic phenomenon can increase the salivary bicarbonate content, which alters calcium phosphate solubility leads to precipitation of calcium and phosphate ions. ${ }^{9}$ A retrograde theory proposed for sialolithiasis suggested that substances or bacteria within the oral cavity might migrate into the salivary ducts and become the nidus for further calcification. ${ }^{7}$ Salivary stagnation increased alkalinity of saliva, infection or inflammation of the salivary duct or gland and physical trauma to salivary duct or gland may predispose to calculus formation. ${ }^{5}$

Salivary calculi are frequently formed in the submandibular duct. The most common sites are where the duct turns around the distal edge of the mylohyoid muscle and just distal to the duct orifice. Untreated calculi can cause obstruction and glandular atrophy, it may exfoliate through the floor of the mouth or present as a cutaneous fistula. ${ }^{10,11}$ The submandibular gland hosts the largest of stones. The largest reported being $55 \mathrm{~mm}$ in length. ${ }^{12}$

Diagnosis of sialolithiasis is easy due to simple and obvious clinical features, but sometimes sialolithiasis of the submandibular gland can be completely asymptomatic. Common symptoms vary from painless-to-severe pain with large glandular swelling with moderate discomfort accompanied by trismus and usually associated with eating food.

Sialograms are effective in detecting ductal and intraglandular calculi. It is, however, contraindicated in acute infection. Ultrasonography (USG) is the simpler method, which demonstrates the sialolith with high accuracy. USG with a high frequency linear transducer $(10-13 \mathrm{MHz})$ is the first choice of investigation for diagnosis of salivary stones. ${ }^{10}$ It has also been reported that sialoliths smaller than $3 \mathrm{~mm}$ may not be detected during ultrasonographic examination, as they will not produce acoustic shadows. Computed tomography is diagnostic, albeit more expensive.

According to Koch et al. ${ }^{13}$ (Fig. 12), the algorithm for the treatment of sialolithiasis depends upon the location and size of the sialolith. Patients presenting with sialolithiasis may benefit from a trial of conservative management, especially if the stone is small. The patient must be well hydrated and the clinician must apply moist warm heat and massage the gland, while sialogogues are used to promote saliva production and flush the stone out of the duct. With gland swelling and sialolithiasis, infection should be assumed and a penicillinaseresistant anti-staphylococcal antibiotic should be prescribed. Most stones will respond to such a regimen, combined with simple sialolithotomy when required. ${ }^{11}$

The use of endoscopic and minimally invasive techniques allows for the greater preservation of the major salivary glands in cases of sialolithiasis. According to literature data, $80-90 \%$ of patients with parotid gland sialolithiasis can be treated using minimally invasive techniques such as sialendoscopy and extracorporeal shock wave lithotripsy (ESWL).14,15,16 It should be remembered that stones larger than $6 \mathrm{~mm}$ in diameter and impacted in the wall of the duct limit the possibility of using sialendoscopy. After performing ESWL, larger stones (Larger than $8-10 \mathrm{~mm}$ in diameter) can successfully be fragmented and then removed using a sialendoscopy. Because of its advantages of minimal bleeding, less scarring, clear vision and minimal postoperative complications, $\mathrm{CO}_{2}$ laser is gaining its popularity in the treatment of sialolithiasis. ${ }^{11}$

\section{CONCLUSION}

Thus we would like to conclude that sialolithiasis though is easy to diagnose can at times mislead the clinician or surgeon. With the advance in sciences, the various advanced diagnostic tools that are available for investigations and the present day scenario of working in a bloodless field can be promising, but the conventional surgical removal of calculi still stands as a gold standard.

\section{REFERENCES}

1. White SC, Pharoah MJ. Oral radiology principles and interpretation. Chapter 27. In: Soft Tissue Calcification and Ossification. Mosby, Missouri 2004;597-614.

2. Alexander KC Leung, Matthew CK, Garth AL Wagner, et al. Multiple sialoliths and a sialolith of unusual size in the submandibular duct. Oral Surg Oral Med Oral Pathol Oral Radiol Endod 1999;87:331-333.

3. Levy DM, Remine WH, Devine KD. Salivary gland calculi. Pain, swelling associated with eating.

JAMA 1962;181:1115-9.

4. Thierbach V, Privman V, Orlian AI. Submandibular gland sialolithiasis: a case report. Gen Dent 2000;48:606-8.

5. Leung AK, Choi MC, Wagner GA. Multiple sialoliths and a sialolith of unusual size in the submandibular duct: a case report. Oral Surg Oral Med Oral Pathol Oral Radiol Endod 1999;87:331-333.

6. Bodner L. Parotid sialolithiasis. J Laryngol Otol 1999;113:266-7.

7. Marchal F, Kurt AM, Dulguerov P, et al. Retrograde theory in sialolithiasis formation. Arch Otolaryngol Head Neck Surg. 2001;127:66-8.

8. Rauch S, Gorlin RJ. Disease of the salivary glands. In: Thomas' Oral Pathology. Gorlin RJ, Goldmann HM (Eds.), Mosby-Year Book Inc; St Louis, Mo 1970;997-1003.

9. Williams MF. Sialolithiasis. Otolaryngol Clin North Am. 1999;32:819-834. 
10. Andretta $M$, et al. Current opinions in sialolithiasis diagnosis and treatment. Acta Otorhinolaryngol Ital 2005;25:145-149.

11. Bodner L. Giant salivary gland calculi: diagnostic imaging and surgical management. Oral Surg Oral Med Oral Pathol Oral Radiol Endod. 2002;94:320-3.

12. Paul D, Chauhan SR. Salivary megalith with a sialocutaneous and sialo-oral fistula: A case report. J Laryngol Otol 1995;109:767-9.

13. Koch M, Zenk J, Iro $\mathrm{H}$. Algorithms for treatment of salivary gland obstructions. Otolaryngol Clin N Am. 2009;42:1173-92.
14. Iro H, Dlugaiczyk J, Zenk J. Current concepts in diagnosis and treatment of sialolithiasis.

Br J Hosp Med 2006;67:24-8.

15. Iro H, Zenk J, Escudier MP, et al. Outcome of minimally invasive management of salivary calculi in 4,691 patients. Laryngoscope 2009;119:263-8.

16. Katz P. New techniques for the treatment of salivary lithiasis: sialoendoscopy and extracorporal lithotripsy: 1773 cases. Ann Otolaryngol Chir Cervicafac 2004;121:123-132. 